\title{
Intrathecal Ketorolac Injection in Albino Rats; Pharmacological and Histological study
}

\author{
*Tarek A. Atia, **Mostafa I. Shalaby，***Nemat M. Al-Baz \\ *Histology, ** Anesthesiology \& ICU, ***Pharmacology Departments; Faculty \\ of Medicine, Al-Azhar University, Cairo, Egypt
}

\begin{abstract}
Introduction: Ketorolac tromethamine is a potent injectable non-steroidal antiinflammatory drug (NSAID). Ketorolac provides successful analgesia after intrathecal or epidural injection. It is frequently used to manage post-operative pain, cancer pain, and arthritis either intrathecally, or intramuscular. However, its long term administration could induce renal toxicity and/or gastro-intestinal ulceration.

Aim of the study: The aim of this study was to assess the analgesic potency of ketorolac after intrathecal injection. Also, we aimed to study the histological effect of ketorolac on the spinal cord and the duodenum after treatment in an animal model.

Methods: 40 adult male albino rats, weighing 250-350 gm, were used and divided into 4 groups, 10 rats each. Group S (control) received $10 \mu 1$ normal saline intrathecally, group K50 received $50 \mu \mathrm{g}$ ketorolac intrathecally, group $\mathrm{K} 50+$ omeprazole (proton pump inhibitor) received $50 \mu \mathrm{g}$ ketorolac intrathecally plus $0.2 \mathrm{mg}$ omeprazole orally, and finally, group K100 received $100 \mu \mathrm{g}$ ketorolac intrathecally. All animals were treated for four successive days.

Result: The rat tail flick latency was longer in K50, K50 + omeprazole, and K100 groups when compared to normal control $(\mathrm{P}=0.002)$. Also, the hind-paw withdrawal latency was longer in treated groups when compared to those of the control group $(\mathrm{P}=0.0001)$. Moreover, K50 group showed decreased phase II response by $61 \%$, K50 + omeprazole group showed decreased phase II by $62 \%$, while K100 group showed decreased it by $76 \%$.

Histological examination revealed no changes in the spinal cord of all treated animals. Also, examination of the duodenum showed normal duodenal mucosa in group K50 and those of group $\mathrm{K} 50$ + omeprazole. On the other hand, cellular infiltration as well as destruction of the mucous acini have been noticed in the duodenum of K100 group.
\end{abstract}

Conclusion: Ketorolac could be a good alternative drug used intrathecally to manage pain. Key word; Ketorolac, analgesics, intrathecal, rats

\section{Introduction}

The study of intrathecal application of drugs to manage pain is important for two reasons. First, it is directly relevant to anesthesia practice in that the intrathecal space is often instrumented as part of perioperative, or chronic pain care. Second, it provides important information regarding mechanisms of analgesic action and of pain transmission, which could guide pharmaceutical development of both intrathecal and systemic drug development. A good example of these rationales is examination of cyclooxygenase (COX) enzyme expression and inhibition in the spinal cord as it relates to pain treatment. COX is expressed in the normal spinal cord in small amounts, both isoforms COX-1 and COX-2. Brocks and, Jamali (1992).
Indeed, the constitutive presence of $\mathrm{COX}-2$ in the spinal cord has been suggested to underlie the early analgesic effect of COX inhibitors after surgery or other peripheral injury and at times before peripheral COX2 expression is increased. After peripheral injury, spinal COX-2 expression is greatly enhanced, leading to increased spinal release of prostaglandins with resultant increased substance-P release and central sensitization. Gillis and Brogden. (1997) For this reason, spinally administered COX inhibitors produce analgesia after injury (Conklin and Eisenach, 2003).

Ketorolac tromethamine is an injectable non-steroidal anti-inflammatory drug (NSAID) approved in 1990 for treating post-operative pain. Ketorolac is 
frequently used to manage postoperative pain, renal colic, arthritis, and cancer pain either intrathecally or intramuscular. Ketorolac has also been reported to provide successful analgesia when injected through epidural way (Gillis and Brogden 1997) .Ketorolac, a peripherally acting drug, has become a popular alternative to opoids for postoperative analgesia, because of its minimal central nervous system side effects specifically respiratory depression, sedation, or nausea and vomiting (Miranda et al., 1993).As a NSAID drug, ketorolac inhibits platelet aggregation, and its long term administration could induce renal toxicity and/or gastro-intestinal ulceration.

Ketorolac has also been reported to provide successful analgesia when injected by intrathecal and epidural way in animal models. To consider the possible reaction of intrathecal ketorolac in man, it is necessary to establish the pharmacokinetic and the effects upon spinal cord after intrathecal delivery in well defined experiment. Analgesic effect of intrathecal administration of ketorolac has been investigated in mouse, rat, and dog models before its recent used in man. (Eisenach $e t$ al., 2002).

\section{Material and Methods}

\section{1- Pharmacological study:}

Forty adult male albino rats weighing $250-350 \mathrm{~g}$ were subjected to the present study. Animals were housed with free access to food and water, and maintained on a 12 hour light/dark cycle. Rats were anesthetized with $2 \%$ halothane in oxygen/air, and then polyethylene catheters (Gauge 27) were inserted through a small incision in the atlanto-occipital membrane, and then passed $8 \mathrm{~cm}$ caudally to the level of the lumber enlargement. To confirm correct placement of the catheter we inject $10 \mu 1$ of $2 \%$ lidocaine followed by $10 \mu 1$ $0.9 \%$ saline to flush the catheter (Yamamoto and, Yaksh. 1992). All animals were developed bilateral motor block of the hind limbs within 30 seconds that lasted within two days.

Animals were divided into 4 groups, 10 rats each. First, group $S$ (control), injected with $10 \mu \mathrm{l}$ sterile saline $0.9 \%$ intrathecally. Second, group K50, where animals were injected intrathecally with $50 \mu \mathrm{g}$ ketorolac dissolved in 10ul normal saline. Third, group K50 + Omeperazole, where animals received $0.2 \mathrm{mg}$ omeperazole (proton pump inhibitor) orally one hour before intrathecal injected with $50 \mu \mathrm{g}$ ketorolac dissolved in $10 \mu \mathrm{l}$ normal saline. Lastly, group K100, where animals were injected intrathecally with $100 \mu \mathrm{g}$ ketorolac dissolved in $10 \mu 1$ normal saline. All doses were given daily for four successive days. At the fourth day, 15 minutes after intrathecal injection rat flick test, and hot plate test were assessed.

\section{A- Rat flick test:}

The nociceptive threshold was measured by latency of the tail flick responses elicited by radiant heat applied to the lower third of the tail. The mean tail flick latency (TFL) of three measurements was taken as the basal threshold. Adjust the amplitude of radiant heat, so that the basal TFL was within 4-6 seconds (Sec.). The TFL taken at 15 minutes intervals after intrathecal injection was expressed as the percentage change from basal tail flick latency, with cut-off limit of $150 \%$ above baseline to avoid unnecessary skin damage. In the present study the cut-off time was 14 Sec.

\section{B- Hot plate test:}

The hind-paw withdrawal latency (HWL) was measured by the hot plate test. The HWL to noxious heat stimulation was tested by the hot plate maintained at temperature of $52^{\circ} \mathrm{C}$. The time of the hindpaw withdrawal was measured in seconds to be referred as HWL to thermal stimulation. The HWL was measured before intrathecal injection of ketorolac as the basal threshold 4-6 Sec. A cut-off limit of $15 \mathrm{Sec}$. was set up to avoid tissue damage (Sun et al., 2003).

\section{C- Formalin test:}

The formalin modified test ( Malmberg, and Yaksh 1993). was performed 15 minutes after the last intrathecal injection. Rats were anesthetized with $2 \%$ halothane in oxygen/air, and then $50 \mathrm{ul}$ of $5 \%$ formalin was injected subcutaneously into the dorsal surface of the right hind-paw with 26-gauge needle. 
After formalin injection, flinches were counted for 1 minute interval at 1 minute, 5 minutes and 10 minutes, and then every 10 minutes for 1 hour. Two phases of spontaneous flinching behavior observed. Phase I; begins immediately after formalin injection, and lasts to the second observation interval (5 minutes). Phase II; begins at the $10^{\text {th }}$ minutes and lasts through 60 minutes. Thus, the mean of the first 2 measurements (at one and five minutes) was the phase I value, and the mean of the remaining measurements was phase II value.

2- Histological study:

At the fifth day, rats were sacrificed, bilateral laminecomty was performed, and spinal cord with the companying catheter tips located at the lumber enlargements were removed from the vertebral canals. Laparotomy was performed; part of the duodenum was removed. Samples were fixed in $10 \%$ formalin buffered saline, embedded in paraffin, and cut out into $6 \mu \mathrm{m}$ thick sections. Duodenal Sections were stained with hematoxylin and eosin stain, and spinal cord sections were stained with Toluidin blue to demonstrate nerve cells, with Nissl granules (Drury and Wallington 1980).

\section{Statistical analysis:}

Data from nociceptive tests were presented as mean \pm SD. Differences between groups were determined by analysis of variance (ANOVA). $\mathrm{P}<0.05$ was considered as significant difference.
A- As regard to the effect of intrathecal administration of ketorolac on rat tail flick responses; the mean TFL was longer in groups $\mathrm{K} 50, \mathrm{~K} 50+$ omeprazol, and K100 than control group (S group), as shown in table- 1 .

B- As regard to the hot plate test, the mean value of HWL was longer in groups K50, K50+ omeprazol, and K100 than control group (S group), as shown in table-2.

C- The effect of intrathecal administration of ketorolac on formalin test is represented in table-3. As regard to phase I, there were non significant difference between ketorolac injected groups and control (S) group, whereas there were significant reduction in the number of flinching in ketorolac injected groups than in $\mathrm{S}$ group.

\section{Histological study:}

- There were no microscopic changes noticed in the spinal cord in treated groups [fig. 2(A\&B) and 3] compared to that of the control [fig. $1(A \& B)$ ]

- Also; microscopic examination of the duodenum of control group showed normal intestinal mucosa, where the villi are lined with intact columnar cells, as well as normal submucosal mucous acini (fig. $4 \& 5$ ).

- Additionally; duodenal mucosa of the treated groups (K50 and $\mathrm{K} 50+$ omeperazol) showed normal structure (fig. 6). On the other hand, the duodenal mucosa of group K100 showed cellular infiltration of the duodenal villi, but with normal mucosal epithelium (fig. 7); and destruction of the submucosal mucous acini (fig. 8).

Pharmacological study:

Table (1): Tail flick latency

\begin{tabular}{|c|c|c|c|c|c|c|}
\hline & $\begin{array}{c}\text { Control } \\
\text { Group }\end{array}$ & K50 Group & $\begin{array}{c}\text { Group K50+ } \\
\text { omeperazol }\end{array}$ & K100 Group & $\mathrm{F}$ & $\mathrm{p}$ \\
\hline Means (S) & 4.9 & $9.7^{*}$ & $9.3^{*}$ & $10.9^{*}$ & 68.64 & 0.002 \\
\hline SD & 0.7379 & \pm 1.1595 & \pm 1.595 & 0.9 & & \\
\hline
\end{tabular}

Mean $=$ Mean value of TFL in seconds

$\mathrm{S}=$ Seconds

$* \mathrm{P}<0.05=$ significant 
Tarek A. Atia et al

Table (2): Hot Plate test

\begin{tabular}{|c|c|c|c|c|c|c|}
\hline & $\begin{array}{c}\text { Control } \\
\text { Group }\end{array}$ & K50 Group & $\begin{array}{c}\text { Group K50+ } \\
\text { omeperazol }\end{array}$ & K100 Group & $\mathrm{F}$ & $\mathrm{p}$ \\
\hline Means (S) & $4.7^{*}$ & $9.5^{*}$ & $9.3^{*}$ & $11^{*}$ & 76.32 & 0.0001 \\
\hline SD & 0.8233 & 1.0801 & 0.9487 & 1.0541 & & \\
\hline
\end{tabular}

Mean $=$ Mean value of HWL in seconds

Table (3): Formalin test

\begin{tabular}{|l|l|c|c|c|c|c|c|}
\hline \multicolumn{2}{|c|}{ Number of flinching } & $\begin{array}{c}\text { Control } \\
\text { Group }\end{array}$ & K50 Group & $\begin{array}{c}\text { Group K50+ } \\
\text { omeperazol }\end{array}$ & K100 Group & F & $\mathrm{p}$ \\
\hline \multirow{2}{*}{ Phase I } & Mean & 16.7 & 15.3 & 15.00 & 13.9 & 94.4 & 0.8 \\
\cline { 2 - 8 } & SD & 2.9078 & 0.9487 & 0.8165 & 0.994 & & \\
\hline \multirow{2}{*}{ Phase II } & Mean & 19.3 & $* 7.90$ & $* 7.500$ & $* 4.8$ & 43.68 & 0.0002 \\
\cline { 2 - 7 } & SD & 0.9487 & 0.9487 & 1.0801 & 0.788 & & \\
\hline $\begin{array}{c}\text { \%of decreased } \\
\text { Phase II responses }\end{array}$ & & & $61 \%$ & $62 \%$ & $76 \%$ & & 0.002 \\
\hline
\end{tabular}

Mean= Mean value of numbers of flinching
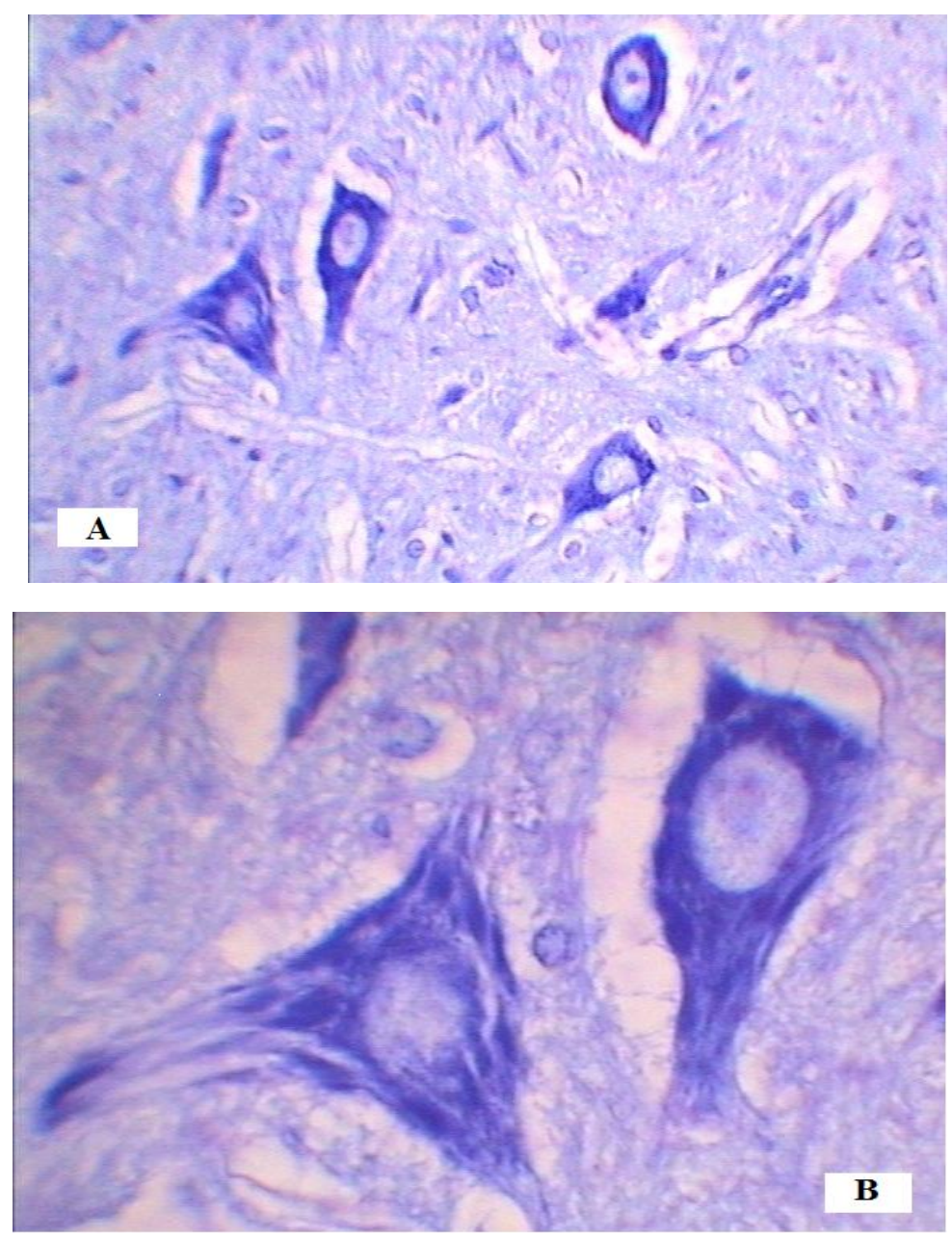

(Fig.1; A\&B): Normal nerve cells of the spinal cord of control rat, showing Nissl granules. Toluidin blue $\quad \mathrm{X250}$ (A) $\quad \mathrm{X} 400(\mathrm{~B})$ 

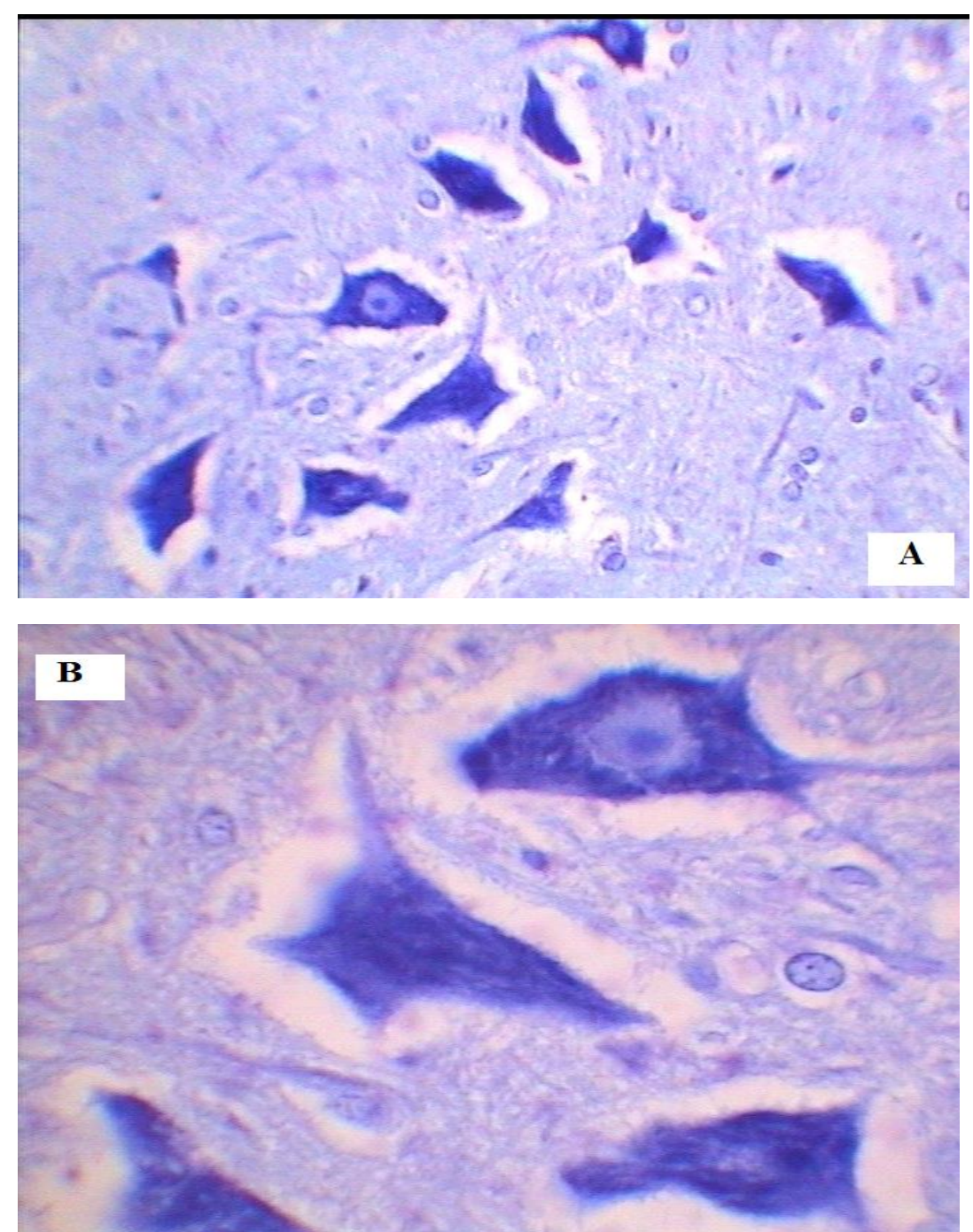

(Fig. 2; A\&B): Section of the spinal cord of ketorolac injected rat (group K50) showing normal nerve cells. Toluidin blue X250 (A) X400 (B)

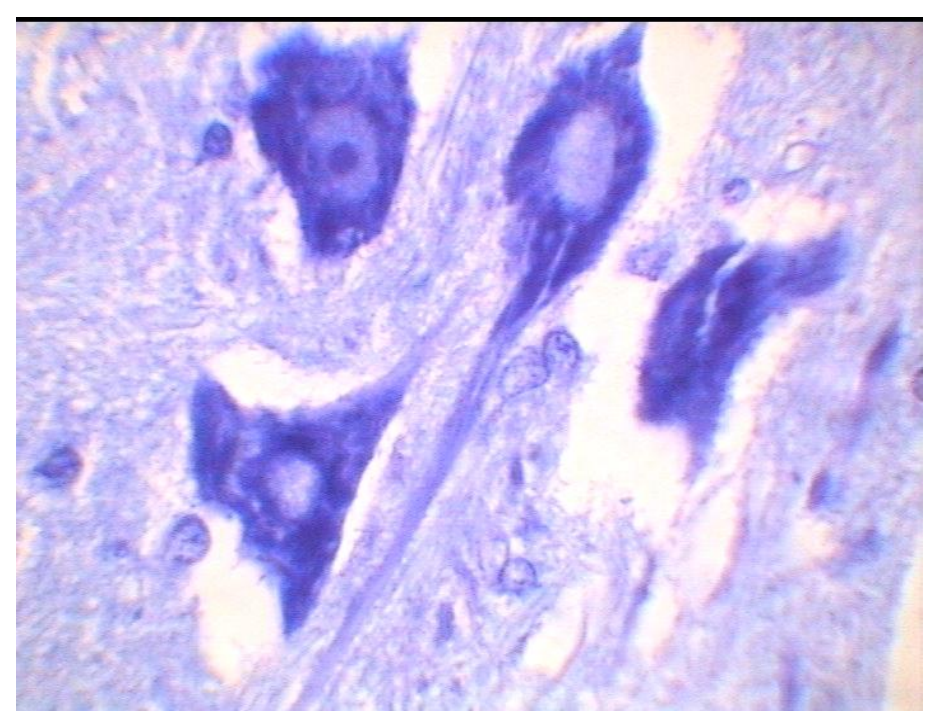

(Fig. 3): Section of the spinal cord of ketorolac injected rat (group K100) showing normal nerve cells.

Toluidin blue X400 
Tarek A. Atia et al

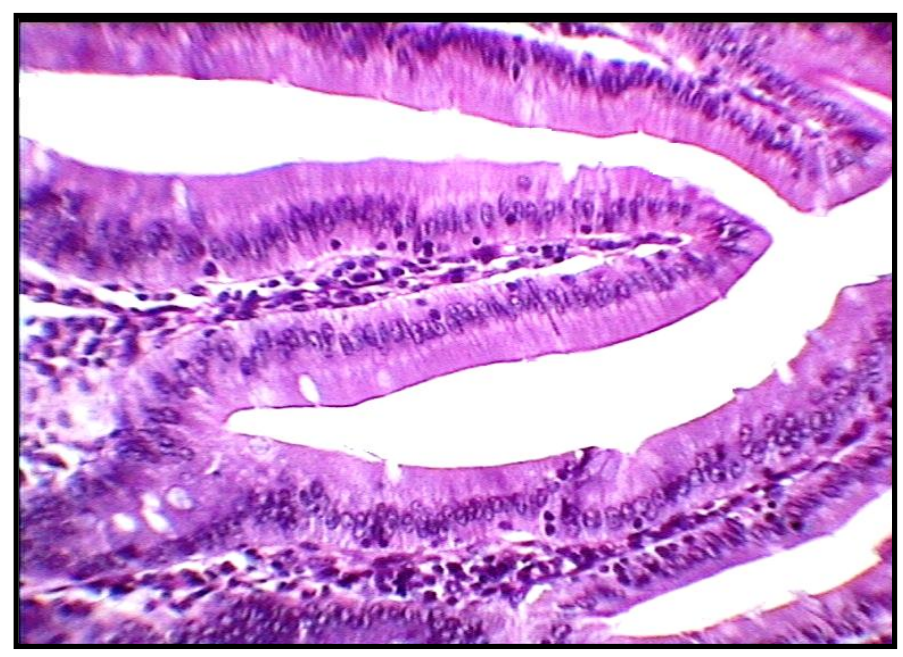

(Fig. 4): Section of the duodenum of control rat showing normal villi with normal immune cell content.

H\&E X400

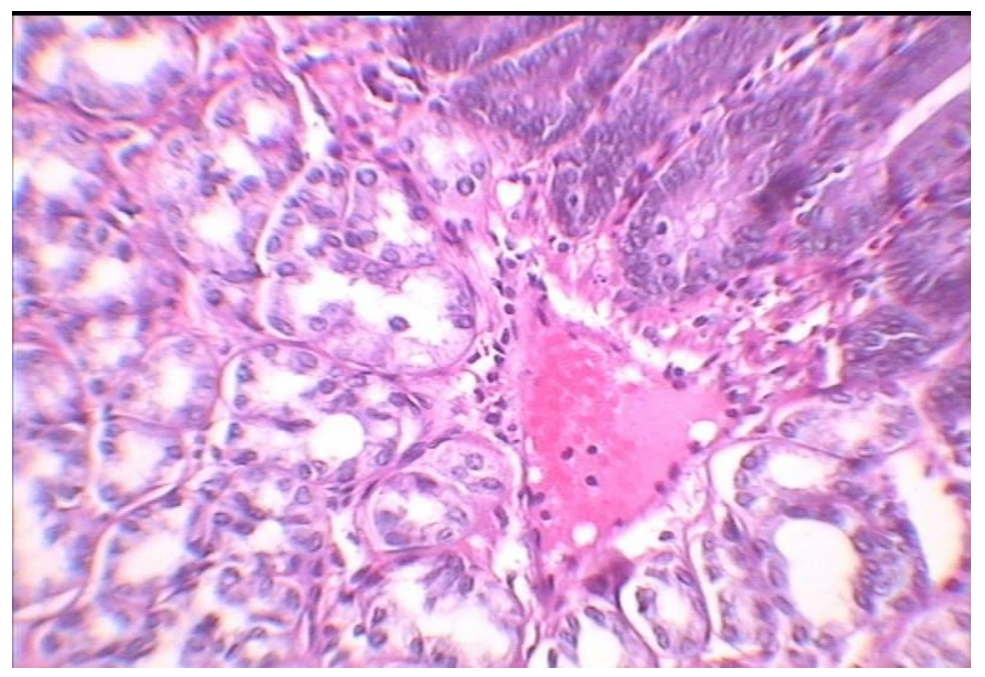

(Fig. 5): Section of the duodenum submucosa of control rat showing normal mucous acini.

H\&E X400

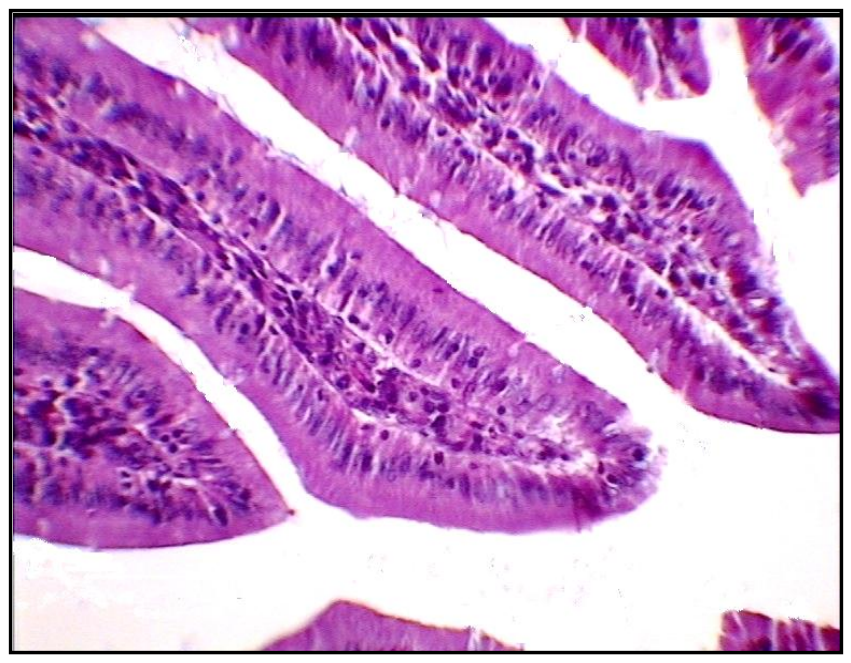

(Fig. 6): Section of the duodenum of ketorolac injected rat (group K50 + omeprazol) showing normal villi and normal immune cell infiltration.

H\&E X400 


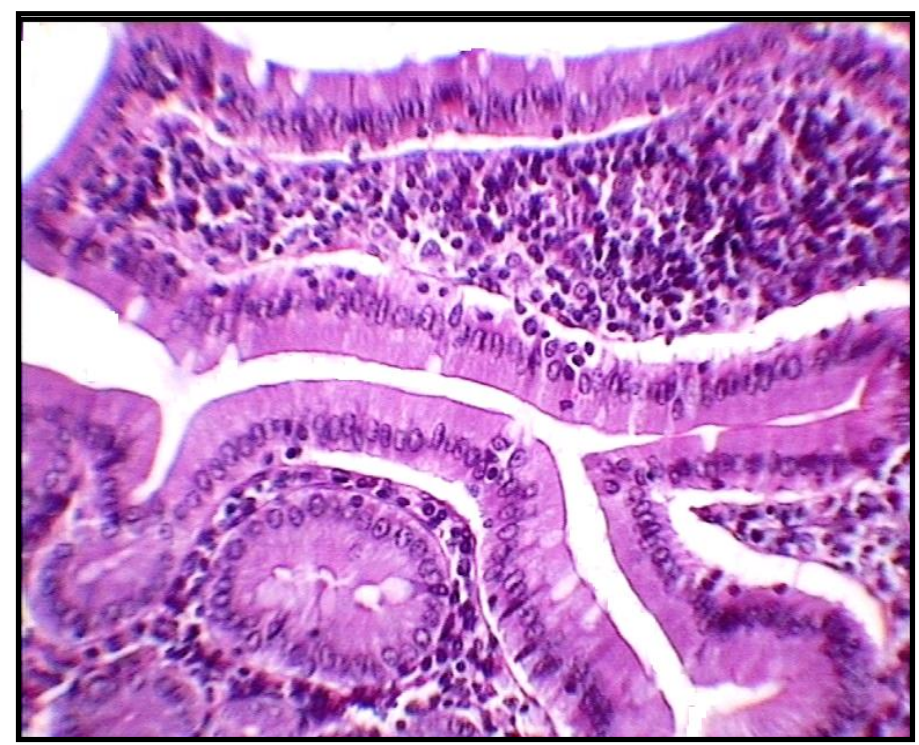

(Fig. 7): Section of the duodenum of ketorolac injected rat (group K100), where the villi show marked cellular infiltration, but with intact epithelium.

H\&E X400

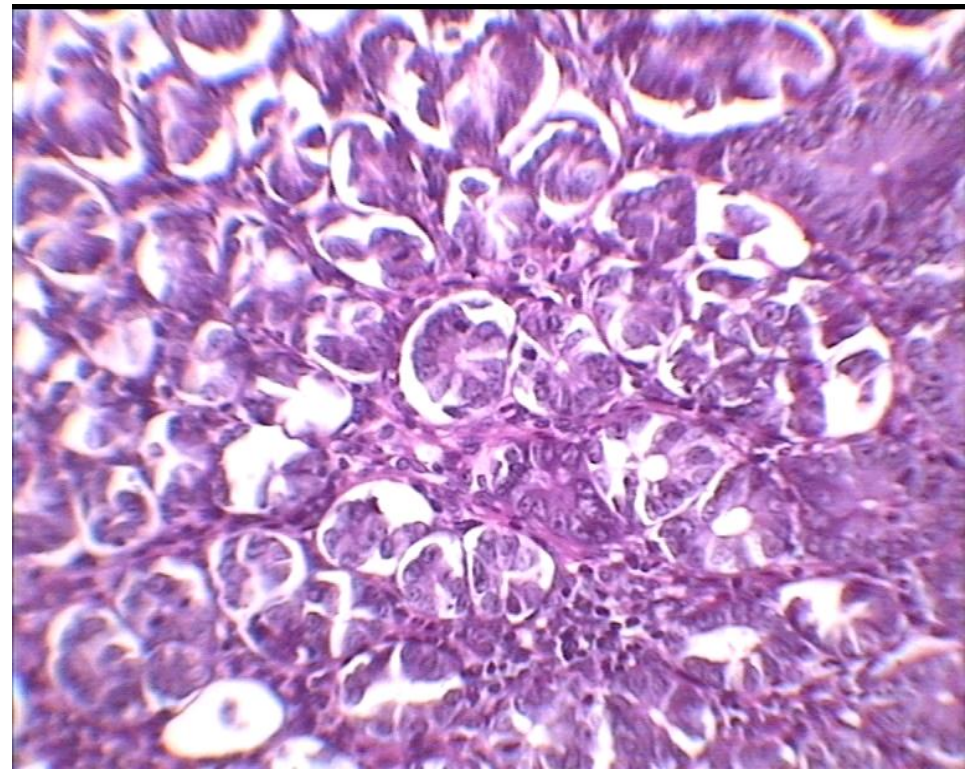

(Fig.8) : Section of the duodenum of ketorolac injected rat (group K100) showing destruction of mucous acini associated with immune cell infiltration.

H\&E X400

\section{Discussion:}

Many different NSAIDs have been evaluated after central administration in animal pain models. Rats, mice, and rabbits have been the most commonly used species in experiments testing acute pain due to mechanical and thermal stimuli or pain associated with inflammation. Drugs that have been studied include indomethacin, flurbiprofen, acetaminophen, ketorolac, ibuprofen, diclofenac, ketoprofen, and others (Malmberg and Yaksh, 1993). The route of administration varies from epidural, spinal, or intracerebroventricular. These drugs have varying degrees of analgesic potency that is not related solely to their ability to inhibit cyclooxygenase (McCormack, 1994). Therefore, other mechanisms must play a role in the analgesic effects of centrally administered NSAIDs. 


\section{Tarek A. Atia et al}

Ketorolac has a potent inhibitor effect upon cyclooxygenase (COX) isozymes (Brocks and Jamali 1992). Several authors have reported the analgesic effect of intrathecal ketorolac in managing pain in man. However, a single intrathecal dose of ketorolac can produce analgesia in rats. Although repeated doses of some drugs such as neostigmine, opiates, or A1 receptors agonist (R-PIA) have not pathological reaction; a single injection of other drugs such as somatostatin or dynorphin induces irreversible motor dysfunction and histological changes in spinal cord (Korkmaz et al.,2004)

In the rat, it has been shown that intrathecal ketorolac injection of $(10 \mu \mathrm{g} / 10$ $\mu \mathrm{l})$ bolus can produce a potent analgesia. However, the maximum dose that can be delivered without any spinal toxicology was $(50 \mu \mathrm{g} / 10 \mu \mathrm{l})$ (Malmberg and Yaksh, 1993). Intrathecal injection of ketorolac is routinely administered once in therapeutic dose for treating postoperative pain, or frequently (but not daily) for managing chronic pain. In the current study we have used the maximum doses $(50 \mu \mathrm{g} / 10 \mu \mathrm{l})$ with and without proton pump inhibitor, and another extra dose $(100 \mu \mathrm{g} / 10 \mu \mathrm{l})$ of ketorolac for four successive days to detect the pharmacological as well as the morphological changes.

Ketorolac prevented nociceptive pain with limited effect on phase I responses in the formalin test contrary to its strong effect on phase II responses. 50 $\mu \mathrm{g}$ ketorolac decreased phase II responses by about $61 \%$, $50 \mu \mathrm{g}$ ketorolac with omeperazol decreased phase II responses by $62 \%$, whereas $100 \mu \mathrm{g}$ ketorolac significantly decreased phase II responses by $76 \%$. This finding is supported by others (Gallivan et al.,2000) where they have found that $50 \mu \mathrm{g}$ ketorolac decreased phase II responses by $65 \%$ and $150 \mu \mathrm{g}$ ketorolac decreased phase II responses by $90 \%$.

As regard to hot plat test, the mean value of HWL increased from $4.7 \mathrm{Sec}$. in the control group(S) to $9.5 \mathrm{Sec}$. in $\mathrm{K} 50$ group, $9.3 \mathrm{Sec}$. in K50+omeperazol group, and $11 \mathrm{Sec}$. in K100 group. As regard to the rat tail flick latency, the mean TFL in control (S) group was $4.9 \mathrm{Sec}$., compared to $0.7 \mathrm{Sec}$., $9.3 \mathrm{Sec}$., and $10.9 \mathrm{Sec}$. in groups K50, K50+ omeperazol, and K100 respectively. This revealed that ketorolac administrated intrathecally exhibited analgesic effect proved by increased the time of HWL and TFL. This in turn is supported by other investigators (Eisenach et al.,2002) where they proved the analgesic effect of ketorolac at doses of 50 $\mu \mathrm{g}$ and $150 \mu \mathrm{g}$.

As regard to the histological changes, ketorolac did not cause any pathological changes in the spinal cord, such as demylination, cellular infiltration, necrosis, or gliosis. On the other hand, histological study of the duodenum revealed mucosal cellular infiltration associated with destruction of the mucous acini in animals of group K100 groups. The previous findings resemble the inflammatory effect of large doses of ketorolac injection, which could progress into duodenal ulceration. Gastrointestinal side effects may be the limiting factor in the use of intrathecal ketorolac for anything but short duration. Korkmaz et al., (2004) reported that intrathecal ketorolac has not any histological changes on the spinal cord, but Schreiner (1998) reported some gastrointestinal ulceration in dogs.

Proton pump inhibitors (omeperazol) bind to the proton pump parietal cells in the gastric mucosa to inhibit hydrogen ions secretion. So, proton pump inhibitors could be used in healing ulcers and erosions; and is used as prophylactic with NSAID (Conklin and Eisenach, 2003).

Conclusion; repeated intrathecal injection of ketorolac reduced the nociceptive responses without neuronal histological changes, but with minimal gastrointestinal cellular infiltration. Ketorolac might become an alternative drug in treating chronic pain with intrathecal injection. Proton pump inhibitors or $\mathrm{H} 2$ antagonist decreased gastrointestinal side effect caused by ketorolac administration.

\section{References:}

1. Brocks DR, Jamali F. (1992): Clinical pharmacokinetics of ketorolac tromethamine. Clinical pharmacokinetics, 23(6): 415-427.

2. Conklin DR, Eisenach JC (2003): Intrathecal ketorolac enhances antiknockiception from clonidine. Anesth Analg., 96(1):191-4. 


\section{Intrathecal Ketorolac Injection in Albino Rats;............}

3. Drury RAB, Wallington FA. (1980): Histological techniques. Oxford University Press, New York, Toronto.

4. Eisenach JC, Curry R, Yaksh TL. (2002): Phase I safety assessment of intrathecal ketorolac. Pain, 99(3): 599-604.

5. Gillis JC, Brogden RN. (1997): Ketorolac: a reappraisal of its pharmacodynamic and pharmacokinetic properties and therapeutic use in pain management. Drug, 53: 139188.

6. Gallivan ST, Johnston SA, Broadstone RV, Jortner BS, Reimer M. (2000). The clinical, cerebrospinal fluid, and histopathologic effects of epidural ketorolac in dogs. Vet Surg. 29(5):436-41.

7. Korkmaz HA, Maltepe F, Erbayraktar S, Yilmaz O, Guray M, Canda MS, Gunerli A, Gokmen N. (2004). Antinociceptive and neurotoxicologic screening of chronic intrathecal administration of ketorolac tromethamine in the rat. Anesth Analg., 98(1):148-52.

8. Malmberg AB, Yaksh TL. (1993): Pharmacology of the spinal action of ketorolac, morphine, ST-91, U50488H, and L-PIA on the formalin test and an isobolographic analysis of the NSAID interaction. Anesthesiology, 79(2):270-81.

9. McCormack K (1994): The Spinal Actions of Nonsteroidal Anti-Inflammatory Drugs and the Dissociation Between Their AntiInflammatory and Analgesic Effects. Drugs., 47:28-45.

10. Miranda HF, Sierralta F, Sierralta F, Pinardi G. (1993): Previous administration of indomethacin or naloxone did not influence ketorolac antinociception in mice. Anesth. Analg., 77: 750-753.

11. Schreiner MS. (1998). Gastric fluid volume: is it really a risk factor for pulmonary aspiration? Anesth Analg., 87(4):754-756.

12. Sun YG, Gu XL, Lundeberg T, Yu LC. (2003): An antinociceptive role of galanin in the arcuate nucleus of hypothalamus in intact rats and rats with inflammation. Pain, 106: 143-150.

13. Yamamoto T, Yaksh TL. (1992): Comparison of the antinociceptive effects of pre- and post-treatment with intrathecal morphine and MK801 and NMDA antagonist on formalin test in the rat. Anesthesiology, 77: 757- 763. 
Tarek A. Atia et al

دراسة هستولوجية وفارماكولوجية

طارق عطية ـ مصطفى شلبيى - نعمة الباز

من اقسام الهستولوجيا والتخدير والادوية بكلية الطب جامعة الازهر - القاهرة

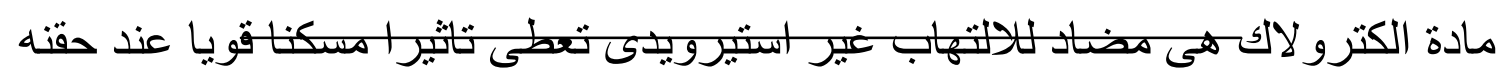

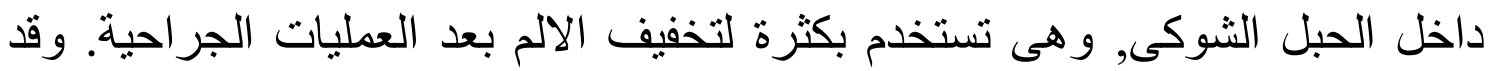

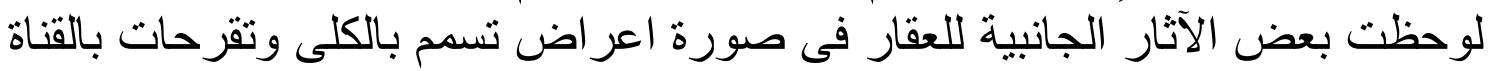

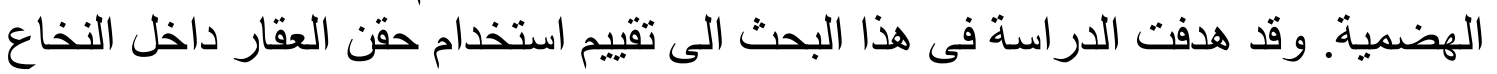

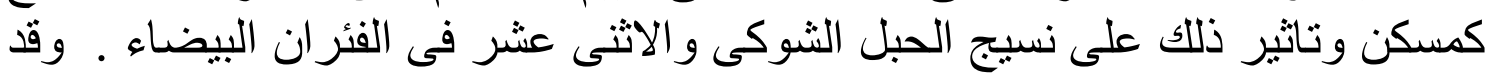

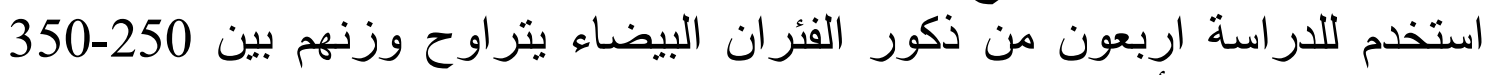

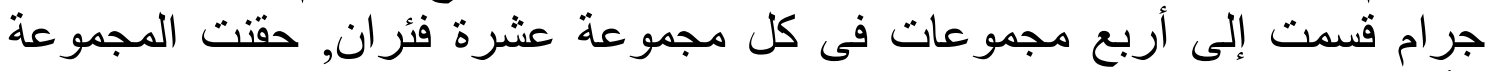

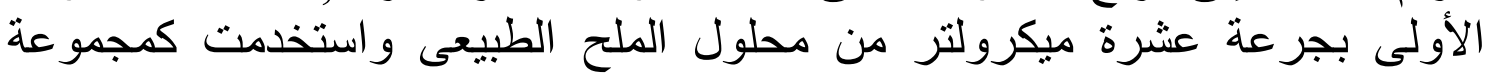

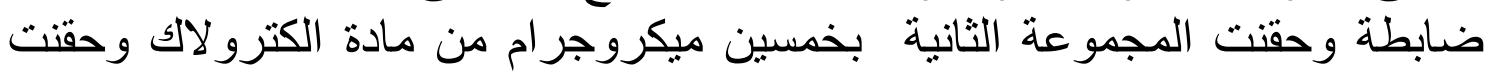

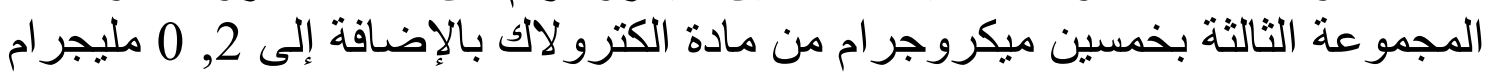

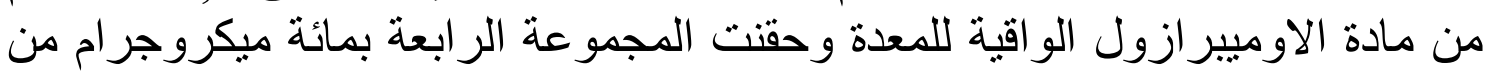

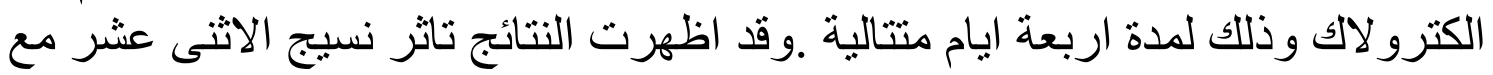

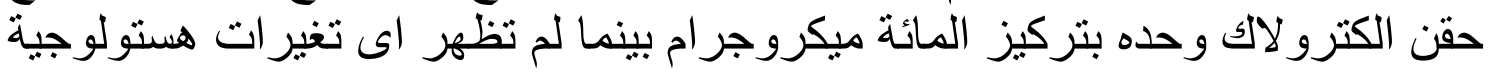

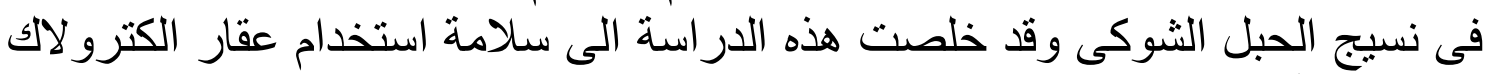

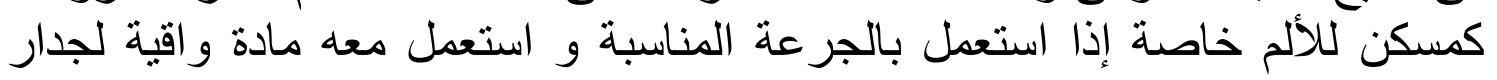

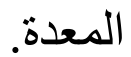

